\title{
Aceitabilidade e estabilidade físico-química de barras de cereais elaboradas à base de aveia e linhaça dourada
}

\author{
Acceptability and physicochemical stability of cereal \\ bars elaborated based on oats and golden flaxseed
}

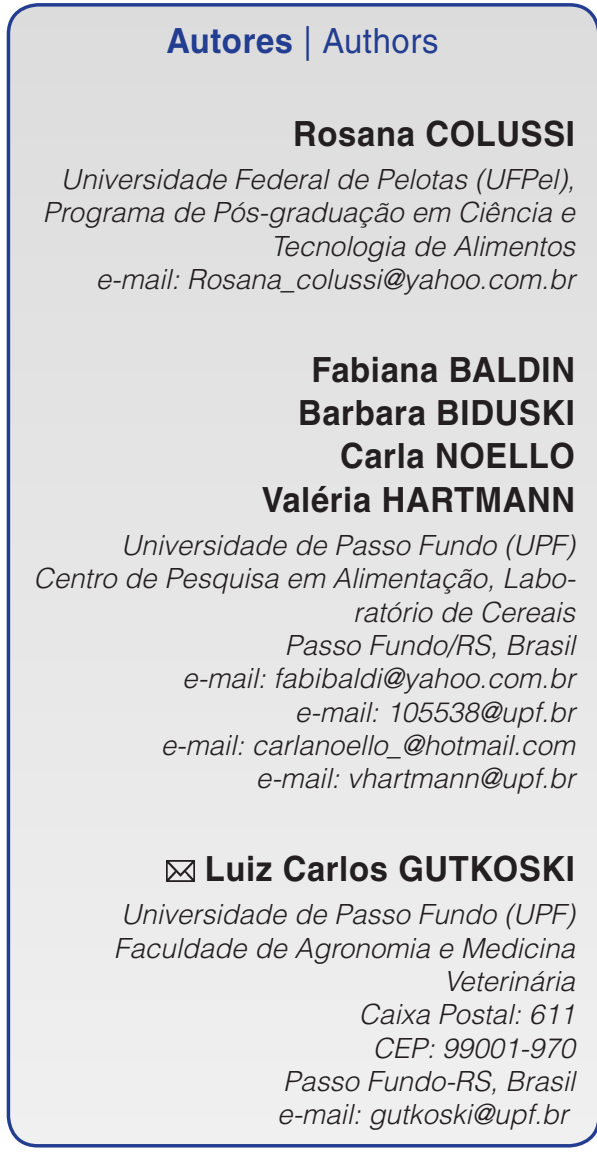

$\square$ Autor Correspondente / Corresponding Author

Recebido / Received: 29/04/2013 Aprovado / Approved: 03/12/2013 Publicado / Published: dez./2013

\section{Resumo}

Matérias-primas de elevado valor nutricional e com propriedades funcionais devem ser utilizadas no desenvolvimento de produtos benéficos à saúde do consumidor. Neste trabalho, objetivou-se estudar combinações de aveia e linhaça dourada na elaboração de barras de cereais, sendo avaliadas a composição química, a aceitabilidade sensorial e a estabilidade pelo período de 60 dias de armazenamento. As barras de cereais foram elaboradas com o emprego de ingredientes secos e agentes ligantes, nas proporções de $70 \%$ e $30 \%$, respectivamente. O delineamento empregado foi o de mistura binária com variações proporcionais nas formulações, sendo realizadas três repetições no ponto central. As barras de cereais foram avaliadas por 35 provadores não treinados quanto à aceitabilidade e à intenção de compra. A estabilidade foi avaliada pela determinação de acidez graxa, índice de peróxidos e atividade de água, e a composição química, pela determinação de umidade, proteínas, cinzas, lipídios, fibra alimentar e carboidratos. Para a composição química, foi realizada a análise de regressão, obtendo-se os coeficientes de determinação e falta de ajuste. Nas demais determinações, os resultados foram analisados pelo emprego da análise da variância (ANOVA) e as médias foram comparadas pelo teste de Tukey a 5\% de significância. A aveia combinada com linhaça dourada pode ser utilizada na elaboração de barras de cereais por apresentar características sensoriais adequadas e ser fonte de fibras. A formulação de melhor aceitabilidade sensorial foi o ponto central, com emprego de $50 \%$ de aveia e $50 \%$ de linhaça dourada. As barras de cereais apresentam boa estabilidade devido à baixa atividade de água e à não formação de peróxidos.

Palavras-chave: Avena sativa; Linum usitatissimum; Composição química; Acidez graxa; Índice de peróxidos.

\section{Summary}

Raw materials with high nutritional value and functional properties should be used in the development of products of benefit to consumer health. The objective of this work was to study combinations of oats and golden flaxseed in the development of cereal bars, evaluating the chemical composition, sensory acceptability and stability during 60 days of storage. The cereal bars were prepared with the use of dry ingredients and binding agents, in proportions of $70 \%$ and $30 \%$, respectively. For this purpose a binary mixture design with variable proportions in the formulations was used, with three repetitions at the central point. The cereal bars were evaluated by 35 untrained tasters with respect to acceptability and purchasing intent. The stability was determined by determining the fatty acidity, peroxide index and water activity, and the chemical composition by determining the moisture, protein, ash, fat, dietary fiber and carbohydrate contents. A regression analysis was carried out with the chemical composition data to obtain the coefficient of determination and lack of fit. For the remaining determinations, the results were analyzed by the analysis of variance (ANOVA) and the means compared by the Tukey test at $5 \%$ significance. Oats combined with golden flaxseed can be used in the development of cereal bars, presenting adequate sensory characteristics and because they are a fibre source. The formulation with the best sensory acceptability was that at the center point, elaborated with $50 \%$ oats and $50 \%$ golden flaxseed. The cereal bars showed good stability due to their low water activity and non-formation of peroxides.

Key words: Avena sativa; Linum usitatissimum; Chemical composition; Fatty acidity; Peroxide index. 


\section{Introdução}

A crescente preocupação por produtos que, além de alimentar, promovam a saúde faz com que alimentos e ingredientes, como a aveia e a linhaça dourada, estejam na lista de preferência de um número cada vez maior de consumidores (IZZO e NINESS, 2001). As propriedades que se atribuem a alimentos funcionais relacionadas à saúde podem ser provenientes de constituintes presentes ou através da adição de ingredientes que modificam as propriedades originais (BOUSTANI e MITCHELL, 1990).

A aveia branca (Avena sativa L.) é um cereal de excelente valor nutricional, que pode ser utilizada na elaboração de produtos de valor calórico reduzido e como fonte de fibras alimentares, atendendo às características de alimento funcional (GUTKOSKI et al., 2009). Devido ao fato de ser rico em antioxidantes, tem crescido o interesse dos consumidores por produtos que contenham este grão em sua formulação (PIOVESANA et al., 2013). Os diferentes constituintes químicos do grão e suas interações permitem a utilização diferenciada pela indústria de alimentos, variando desde estruturas de pequena granulometria, como farinhas, até alimentos floculados, que dependem de fatores genéticos e ambientais, manejo de produção e pós-colheita (BUTT et al., 2008). $\mathrm{O}$ amido de aveia apresenta comportamento diferenciado em relação aos demais cereais, sugerindo a aplicação como espessante em razão da alta estabilidade à retrogradação (GALDEANO et al., 2009). A aveia possui função nutritiva básica e propriedades fisiológicas benéficas, sendo também considerada um grão integral por apresentar, após o seu processamento, o mesmo balanço de nutrientes encontrado na matéria-prima original (MARQUART et al., 2000).

A linhaça dourada (Linum usitatissimum. L) é reconhecidamente uma das maiores fontes de ácidos graxos essenciais, possuindo ainda vários compostos fenólicos, conhecidos por exercerem atividade antioxidante (GALVÃO et al., 2008). Contém ácidos graxos ômega-3 (60\%) e ômega-6 (16\%), minerais, vitaminas, fibras e lignanas, sendo esta uma fibra que estimula a imunidade e reduz o colesterol total e o LDL-colesterol (COLPO et al., 2006). Atribui-se ao grão o sabor e o aroma de nozes, podendo ser facilmente incorporado a diversos produtos.

As barras de cereais são multicomponentes com formulação complexa, cuja combinação de ingredientes deve garantir que estes se complementem mutuamente nas características de sabor, textura e propriedades físicas (IZZO e NINESS, 2001). As barras de cereais são alimentos de fácil consumo e requerem pouco ou nenhum preparo; entretanto, durante muito tempo, seus valores nutritivos foram pouco enfatizados. Os principais aspectos considerados na elaboração desse produto incluem a escolha do cereal; a seleção do carboidrato apropriado, de forma a manter o equilíbrio entre o sabor e a vida de prateleira; o enriquecimento com vários nutrientes, e sua estabilidade no processamento. A associação entre barra de cereais e alimentos saudáveis é uma tendência no setor de alimentos, o que beneficia o mercado destes produtos. Nesse contexto, o trabalho objetivou estudar combinações de aveia e linhaça dourada na elaboração de barras de cereais, sendo estas submetidas à avaliação da composição química, à aceitabilidade sensorial e à estabilidade após a elaboração. Note-se que as mesmas foram armazenadas pelo período de 60 dias e novamente analisadas quanto a aceitabilidade sensorial e estabilidade.

\section{Material e métodos}

\subsection{Material}

As barras de cereais foram elaboradas com emprego da mistura de flocos e farinha de aveia, em proporção de 50\% cada, fornecida pela Nat Cereais e Alimentos Ltda. (Lagoa Vermelha-RS), e linhaça dourada, fornecida pela Cisbra Ltda. Os demais ingredientes - flocos de arroz, maltodextrina, uva-passa, gelatina hidrolisada, ácido cítrico, aroma natural de baunilha, glicose de milho, sacarose e xarope de sorbitol - foram adquiridos no comércio da cidade de Passo Fundo-RS.

\subsection{Metodologia}

\subsubsection{Elaboração das barras de cereais}

As barras de cereais à base de aveia e linhaça dourada foram elaboradas com o emprego de ingredientes secos: flocos de arroz, aveia e linhaça dourada (CISBRA Ltda.), uva-passa (Hemmer Alimentos) e agentes ligantes, como maltodextrina (ADS Laboratório Nutricional Ltda.), gelatina hidrolisada (Rebiéri Gelatinas Ltda.), ácido cítrico e sorbitol (Lab Synth), aroma de baunilha (Fleischmann), glicose de milho (Dulcini S/A), sacarose da marca Dolce (NovAmérica S.A.) e água, nas proporções de $70 \%$ e $30 \%$, respectivamente (Tabela 1). Os ingredientes secos foram pesados em balança marca Ohaus Corporation, modelo AR5120, China, tostados em forno elétrico marca Fischer, modelo 090103, Brasil, e adicionados à calda, elaborada através da dissolução dos agentes ligantes. A mistura foi submetida à concentração sob cozimento à pressão atmosférica até $75^{\circ}$ Brix. As barras de cereais foram moldadas e resfriadas, embaladas em filmes de PVC, e armazenadas sob incidência de luz ambiente, em prateleiras à temperatura ambiente $\left(22^{\circ} \mathrm{C} \pm 5^{\circ} \mathrm{C}\right)$. As análises de composição química, aceitabilidade sensorial e estabilidade foram realizadas nos Laboratórios do Centro de Pesquisa e Alimentação da Universidade de Passo Fundo. Nos estudos de aceitabilidade e vida de 
Aceitabilidade e estabilidade físico-química de barras de cereais elaboradas à base de aveia e linhaça dourada COLUSSI, R. et al.

Tabela 1. Formulação de barras de cereais elaboradas com mistura binária de aveia e linhaça dourada.

\begin{tabular}{|c|c|c|c|c|c|c|c|}
\hline Ingrediente & $\mathrm{T} 1(\mathrm{~g})$ & $\mathrm{T} 2(\mathrm{~g})$ & $\mathrm{T}^{*}(\mathrm{~g})$ & $\mathrm{T}^{*}$ (g) & $\mathrm{T}^{*}(\mathrm{~g})$ & T6 (g) & T7 (g) \\
\hline Flocos de arroz & 30 & 30 & 30 & 30 & 30 & 30 & 30 \\
\hline Maltodextrina & 26,5 & 26,5 & 26,5 & 26,5 & 26,5 & 26,5 & 26,5 \\
\hline Uva-passa & 20 & 20 & 20 & 20 & 20 & 20 & 20 \\
\hline Gelatina hidrolisada & 17,5 & 17,5 & 17,5 & 17,5 & 17,5 & 17,5 & 17,5 \\
\hline Ácido cítrico & 0,2 & 0,2 & 0,2 & 0,2 & 0,2 & 0,2 & 0,2 \\
\hline Aroma de baunilha & 0,8 & 0,8 & 0,8 & 0,8 & 0,8 & 0,8 & 0,8 \\
\hline Glicose de milho & 35 & 35 & 35 & 35 & 35 & 35 & 35 \\
\hline Sacarose & 40 & 40 & 40 & 40 & 40 & 40 & 40 \\
\hline Sorbitol & 75 & 75 & 75 & 75 & 75 & 75 & 75 \\
\hline Água & 200 & 200 & 200 & 200 & 200 & 200 & 200 \\
\hline Aveia & 255 & 0 & 127,5 & 127,5 & 127,5 & 63,75 & 191,25 \\
\hline Linhaça dourada & 0 & 255 & 127,5 & 127,5 & 127,5 & 191,25 & 63,75 \\
\hline
\end{tabular}

*Ponto central.

prateleira, as barras de cereais foram analisadas quanto a textura, aroma/odor, sabor, impressão global, intenção de compra, atividade de água, índice de peróxido e acidez graxa, nos tempos zero e 60 dias de armazenamento.

\subsubsection{Delineamento experimental}

O delineamento empregado para estudar o efeito combinado das variáveis aveia e linhaça dourada foi o de mistura binária com variações proporcionais nas formulações, e a realização de três repetições no ponto central (BARROS NETO et al., 2003). As formulações de cada tratamento estão apresentadas na Tabela 1.

\subsection{Análises}

\subsubsection{Aceitabilidade sensorial}

Este trabalho foi submetido e aprovado pelo Comitê de Ética em Pesquisa da Universidade de Passo Fundo, Passo Fundo-RS, e todos os participantes assinaram o Termo de Consentimento Livre e Esclarecido (Projeto n. ${ }^{\circ}:$ 92406). As formulações de barras de cereais à base de aveia e linhaça dourada foram avaliadas quanto à aceitação, pelos atributos: textura, aroma/odor, sabor, impressão global e intenção de compra, através do emprego do teste afetivo de aceitabilidade, realizado em cabines individuais (STONE e SIDEL, 1993). Os 35 provadores não treinados, com idade acima de 18 anos, foram selecionados entre funcionários, alunos e visitantes da Universidade, com base no interesse e na disponibilidade de participar do teste sensorial. A avaliação da aceitação foi realizada com o emprego de escala hedônica estruturada verbal de 9 pontos: 1 = desgostei muitíssimo a 9 = gostei muitíssimo. Para a intenção de compra, utilizou-se escala estruturada verbal de 5 pontos: 1 = certamente eu não compraria a 5 = certamente eu compraria.

\subsubsection{Estabilidade ao armazenamento}

As barras de cereais foram embaladas em filme de PVC, armazenadas à temperatura ambiente e sob exposição à luz ambiente, sendo avaliados os parâmetros acidez graxa, índice de peróxidos e atividade de água após a elaboração e 60 dias de armazenamento. A determinação de acidez graxa foi realizada de acordo com o método n. ${ }^{\circ}$ 02-02A da AACC (2009), sendo os lípídios extraídos pelo emprego do método Bligh e Dyer (1959) e realizada a titulação com uso de $\mathrm{NaOH}$ de lipídios solubilizados em tolueno.

O índice de peróxido foi determinado de acordo com o método Cd 8-53 da AOCS (FIRESTONE, 2012) e os valores foram expressos em miliequivalentes de peróxido por $1000 \mathrm{~g}$ de amostra, que oxidam o iodeto de potássio nas condições do teste. A determinação de atividade de água foi realizada pelo emprego do equipamento Testo, modelo 650, Alemanha, à temperatura constante (22 ${ }^{\circ} \mathrm{C} \pm 1$ ). As análises de acidez graxa, índice de peróxidos e atividade de água foram realizadas em triplicata.

\subsubsection{Composição centesimal}

As determinações de umidade, proteínas e cinzas foram realizadas de acordo com os procedimentos da AACC (2009), métodos números 44-15 A, 46-12 e 08-12, respectivamente. $O$ teor de lipídios foi determinado de acordo com o método Bligh e Dyer (1959); a fibra alimentar, segundo o procedimento da AOAC (FIRESTONE, 2012), método número 991.43, e o teor de carboidratos, estimado por diferença, diminuindo-se de 100 o somatório de proteínas, lipídios, cinzas, umidade e fibra alimentar. As análises foram realizadas em triplicata.

O valor calórico foi calculado a partir dos dados de composição centesimal aproximada, de acordo com Brasil (2003). No cálculo, foram usados os fatores de conversão de 4 kcal para carboidratos e proteínas, e de 9 kcal para lipídios, sendo os resultados expressos em kcal por $100 \mathrm{~g}$. 


\subsection{Análise estatística}

Os resultados da aceitabilidade sensorial e da estabilidade ao armazenamento foram analisados pelo emprego da análise da variância (ANOVA) e, nos modelos significativos, as médias foram comparadas pelo teste de Tukey a 5\% de significância. Para os resultados de composição química, foi empregada a análise de regressão, obtendo-se os coeficientes de determinação e de falta de ajuste (BARROS NETO et al., 2003).

\section{Resultados e discussão}

\subsection{Aceitabilidade}

As notas atribuídas pelos provadores das barras de cereais avaliadas quanto à aceitabilidade sensorial e à intenção de compra, após a elaboração e aos 60 dias de armazenamento, estão apresentadas nas Tabelas 2 e 3 , respectivamente.

As formulações de barra de cereais elaboradas com aveia e linhaça dourada apresentaram boa aceitação nos atributos sensoriais avaliados, sendo superior em comparação aos resultados apresentados por Brito et al. (2004), na avaliação de atributos sensoriais de barras de cereais caseiras.

As barras de cereais elaboradas com $50 \%$ de aveia e $50 \%$ de linhaça dourada (ponto central) apresentaram diferença significativa $(p<0,05)$ para aceitabilidade de textura, aroma/odor e sabor, quando comparado ao T1, e não apresentou diferença estatística quando comparado ao T2, T6 e T7. Em relação à impressão global, todos os tratamentos foram aceitos
O tratamento com $100 \%$ de aveia (T1) apresentou menores valores nos atributos textura, aroma/odor e sabor, sendo estatisticamente inferior ao ponto central, demonstrando menor aceitação do consumidor por barras de cereais elaboradas somente com aveia.

Os tratamentos com $100 \%$ de linhaça dourada (T2), 25\% de aveia e $75 \%$ de linhaça dourada (T6), e $75 \%$ de aveia e $25 \%$ de linhaça dourada (T7) não apresentaram diferenças estatísticas significativas entre si, indicando que as quantidades de $75 \%$ de aveia ou de linhaça dourada, ou o emprego de 100\% de linhaça não interferem na aceitação das barras de cereais.

Em relação à intenção de compra, o ponto central apresentou valores superiores, diferindo significativamente dos tratamentos com 100\% de aveia ou $100 \%$ de linhaça. O emprego de aveia e linhaça na formulação melhorou a intenção de compra dos produtos elaborados. Aguiar et al. (2008) afirmam que o consumidor observa os atributos aparência, cor, aroma e sabor, entre outros aspectos, no momento da intenção de compra de um produto.

Após os 60 dias de armazenamento, o ponto central continuou apresentando valores significativamente superiores $(p<0,05)$ quando comparado aos tratamentos com maior concentração de aveia T1 e T7, em todos os atributos avaliados. Apesar das alterações físicoquímicas ocorridas durante o período de armazenamento, que influenciaram nas propriedades sensoriais das barras de cereais, os tratamentos T2 e T6 não diferiram significativamente $(p>0,05)$ quando comparados ao ponto central, com exceção do atributo aroma/odor do tratamento T2.

Tabela 2. Valores dos atributos sensoriais textura, aroma/odor, sabor, impressão global, e intenção de compra de barras de cereais à base de aveia e linhaça dourada após a elaboração.

\begin{tabular}{cccccc}
\hline Tratamento & Textura & Aroma/ Odor & Sabor & Impressão global & Intenção de compra \\
\hline T1 & $6,68^{\mathrm{b}} \pm 1,47$ & $6,54^{\mathrm{b}} \pm 1,24$ & $6,25^{\mathrm{b}} \pm 1,91$ & $6,25^{\mathrm{a}} \pm 1,73$ & $3,05^{\mathrm{b}} \pm 1,16$ \\
T2 & $7,02^{\mathrm{ab}} \pm 1,29$ & $6,85^{\mathrm{ab}} \pm 1,57$ & $6,37^{\mathrm{ab}} \pm 1,78$ & $6,62^{\mathrm{a}} \pm 1,43$ & $2,97^{\mathrm{b}} \pm 0,89$ \\
Ponto central & $7,68^{\mathrm{a}} \pm 1,05$ & $7,62^{\mathrm{a}} \pm 1,19$ & $7,42^{\mathrm{a}} \pm 1,19$ & $7,30^{\mathrm{a}} \pm 1,41$ & $3,77^{\mathrm{a}} \pm 0,87$ \\
T6 & $7,00^{\mathrm{ab}} \pm 1,57$ & $6,94^{\mathrm{ab}} \pm 1,30$ & $6,74^{\mathrm{ab}} \pm 1,52$ & $6,80^{\mathrm{a}} \pm 1,35$ & $3,40^{\mathrm{ab}} \pm 0,94$ \\
T7 & $7,00^{\mathrm{ab}} \pm 1,35$ & $6,88^{\mathrm{ab}} \pm 1,32$ & $6,77^{\mathrm{ab}} \pm 1,69$ & $6,65^{\mathrm{a}} \pm 1,47$ & $3,34^{\mathrm{ab}} \pm 0,93$ \\
\hline
\end{tabular}

${ }^{1}$ Letras minúsculas distintas na mesma coluna representam diferença significativa entre as médias submetidas ao teste de Tukey a $5 \%$ de probabilidade de erro.

Tabela 3. Valores dos atributos sensoriais textura, aroma/odor, sabor, impressão global, e intenção de compra de barras de cereais à base de aveia e linhaça dourada, após 60 dias de armazenamento.

\begin{tabular}{|c|c|c|c|c|c|}
\hline Tratamento $^{1}$ & Textura & Aroma/ Odor & Sabor & Impressão global & Intenção de compra \\
\hline $\mathrm{T} 1$ & $5,66^{b} \pm 1,57$ & $6,23^{c} \pm 1,41$ & $4,86^{c} \pm 1,41$ & $5,57^{\mathrm{c}} \pm 2,12$ & $2,46^{c} \pm 1,41$ \\
\hline T2 & $6,54^{\mathrm{ab}} \pm 1,38$ & $6,91^{b c} \pm 0,71$ & $6,34^{\mathrm{ab}} \pm 1,41$ & $6,60^{\mathrm{ab}} \pm 1,41$ & $3,23^{\mathrm{ab}} \pm 1,09$ \\
\hline Ponto central & $7,20^{a} \pm 1,41$ & $7,71^{\mathrm{a}} \pm 0,71$ & $7,37^{a} \pm 1,21$ & $7,31^{a} \pm 0,99$ & $3,77^{a} \pm 0,73$ \\
\hline T6 & $6,57^{\mathrm{ab}} \pm 2,12$ & $7,06^{\mathrm{ab}} \pm 1,03$ & $6,77^{\mathrm{ab}} \pm 2,83$ & $6,94^{\mathrm{ab}} \pm 2,83$ & $3,49^{\mathrm{ab}} \pm 2,12$ \\
\hline T7 & $6,14^{b} \pm 1,41$ & $6,80^{b c} \pm 1,39$ & $6,26^{b} \pm 1,77$ & $6,37^{b c} \pm 1,41$ & $3,14^{b} \pm 0,88$ \\
\hline
\end{tabular}

${ }^{1}$ Letras minúsculas distintas na mesma coluna representam diferença significativa entre as médias submetidas ao teste de Tukey a $5 \%$ de probabilidade de erro. 


\subsection{Estabilidade}

A atividade de água dos tratamentos variou de 0,562 a 0,607 (Tabela 4), sendo significativamente superior no ponto central e com menores valores nos experimentos $T 1$ e $T 7$, o que pode ser devido à maior concentração de aveia na formulação. Com o período de armazenamento, a atividade de água apresentou redução no valor do ponto central e aumento nos demais tratamentos. A atividade de água nas amostras analisadas encontrou-se dentro de valores desejados para a redução do desenvolvimento de microrganismos deteriorantes.

A ingesta da maioria dos alimentos é com atividade de água superior a 0,8; isso garante que o alimento esteja tenro e úmido, facilitando a mastigação e tornando-se mais agradável ao paladar. Porém, nesta faixa de $a_{w}$, os alimentos estão sob risco de desenvolvimento de microrganismos. Os alimentos de $a_{w}$ intermediária, envolvendo uma série de produtos naturais ou parcialmente desidratados, com $\mathrm{a}_{\mathrm{w}}$ oscilando entre 0,60 e 0,85 , estão sujeitos à deterioração, provocada principalmente pelo crescimento de bolores e leveduras (FENNEMA, 2000). Gutkoski et al. (2007), em estudo de barras de cereais à base de aveia com alto teor de fibra alimentar, verificaram que os valores de atividade de água foram entre 0,59 e 0,70, estando os produtos em acordo com as especificações sanitárias, mostrando-se microbiologicamente estáveis durante 60 dias de armazenamento.

A acidez graxa aumentou proporcionalmente à quantidade de aveia empregada nos tratamentos, sendo significativamente superior no T1, com $100 \%$ de aveia. Esses resultados indicam que a aveia foi responsável pelos elevados valores de acidez graxa dos tratamentos.

Segundo Peterson et al. (2001), a alta acidez graxa presente na aveia pode ocorrer devido à rancidez hidrolítica através das enzimas lipoxigenase e lipase, necessitando ser realizada a inativação por tratamento hidrotérmico. Entretanto, a rancidez hidrolítica não enzimática também ocorre lentamente com o tempo. Segundo Gutkoski et al. (2007), o aumento da rancidez hidrolítica pode ocorrer em razão de a aveia estar exposta a diversos fatores que influenciam na estabilidade da mesma, como cultivar, local de cultivo, fatores genéticos e ambientais.

As barras de cereal avaliadas não apresentaram valores para índice de peróxidos durante o período de armazenamento estudado. Isto pode ser explicado pela presença de propriedades antioxidantes e compostos fenólicos, tanto na linhaça dourada quanto na aveia. Estas matérias-primas, em virtude do seu alto teor de lipídios, quando empregadas como ingredientes de alimentos processados, podem exercer efeito na redução da oxidação lipídica (KLAJN et al., 2012). Na aveia, os ácidos graxos livres poli-insaturados podem ser oxidados, levando à formação de compostos com características de sabor desagradável em longos períodos de armazenamento (PETERSON et al., 2001).

\subsection{Composição química}

A partir dos dados experimentais das variáveis estudadas para a composição química, estabeleceram-se os modelos de regressão em função das condições experimentais empregadas. Foi avaliada a significância das mesmas no nível de $5 \%$ de probabilidade de erro. 0 aceite dos modelos pode ser verificado na Tabela 5, em que os coeficientes de determinação $\left(R^{2}\right)$ apresentam valores entre 0,87 e 0,99 da variância total das respostas. Os modelos de regressão foram significativos $(p \leq 0,05)$ e os coeficientes de determinação das respostas estudadas mostraram-se elevados, indicando que os mesmos podem representar o comportamento das variáveis. Nas variáveis de resposta fibras e valor calórico total (VCT), os efeitos lineares e as interações foram significativos, enquanto que, para as proteínas, somente foram significativos os efeitos lineares, como apresentado na Tabela 5. Nas respostas proteínas, fibras e valor calórico total (VCT) de barras de cereais elaboradas com aveia e linhaça dourada, não foi verificada falta de ajuste, conforme avaliado em análise estatística.

Como se pode observar na Figura 1, quanto maior a concentração de linhaça dourada, maior é a porcentagem de proteínas nas barras, o que pode ser explicado pelo grande teor de proteínas encontradas no grão de linhaça in natura. O teor de proteínas das barras de cereais variou entre $11,33 \%$ e 13,27\% (Figura 1), sendo superior aos

Tabela 4. Atividade de água $\left(\mathrm{a}_{\mathrm{w}}\right)$ e acidez graxa $(\mathrm{AG})$ de barras de cereais elaboradas com aveia e linhaça dourada nos tempos zero e 60 dias de armazenamento.

\begin{tabular}{ccccc} 
Tratamento & $\mathbf{a}_{\mathbf{w}}$ tempo zero & $\mathbf{a}_{\mathbf{w}} \mathbf{6 0}$ dias & AG tempo zero & AG $\mathbf{6 0}$ dias \\
\hline T1 & $0,562^{\mathrm{c}} \pm 0,003$ & $0,614^{\mathrm{a}} \pm 0,003$ & $10,40^{\mathrm{a}} \pm 1,435$ & $20,67^{\mathrm{a}} \pm 1,025$ \\
T2 & $0,584^{\mathrm{b}} \pm 0,003$ & $0,614^{\mathrm{a}} \pm 0,004$ & $2,38^{\mathrm{b}} \pm 0,339$ & $2,46^{\mathrm{c}} \pm 0,410$ \\
Ponto central & $0,607^{\mathrm{a}} \pm 0,003$ & $0,601^{\mathrm{b}} \pm 0,001$ & $3,17^{\mathrm{b}} \pm 0,367$ & $4,85^{\mathrm{c}} \pm 0,655^{\mathrm{b}}$ \\
T6 & $0,588^{\mathrm{b}} \pm 0,005$ & $0,619^{\mathrm{a}} \pm 0,002$ & $2,28^{\mathrm{b}} \pm 0,197$ & $3,76^{\mathrm{c}} \pm 0,226$ \\
T7 & $0,562^{\mathrm{c}} \pm 0,003$ & $0,612^{\mathrm{a}} \pm 0,001$ & $4,30^{\mathrm{b}} \pm 0,056$ & $8,97^{\mathrm{b}} \pm 1,152$ \\
\hline
\end{tabular}

${ }^{1}$ Letras minúsculas distintas na mesma coluna representam diferença significativa entre as médias submetidas ao teste de Tukey a $5 \%$ de probabilidade de erro. 
Aceitabilidade e estabilidade físico-química de barras de cereais elaboradas à base de aveia e linhaça dourada COLUSSI, R. et al.

Tabela 5. Modelo de regressão, coeficiente de determinação $\left(R^{2}\right)$, nível de significância e falta de ajuste para as respostas proteínas, fibras e valor calórico total (VCT) de barras de cereais elaboradas com aveia e linhaça dourada.

\begin{tabular}{ccccc} 
Resposta & \multicolumn{1}{c}{ Modelo } & $\mathbf{R}^{2}$ & Probabilidade & Falta de ajuste \\
Proteínas & $y=0,1131 x_{1}+0,1311 x_{2}$ & 0,8792 & 0,00018 & 0,6916 \\
Fibras & $y=0,1249 x_{1}+0,1949 x_{2}-0,0014 x_{1} x_{2}$ & 0,8982 & 0,0103 & 0,7324 \\
VCT & $y=3,2278 x_{1}+3,8573 x_{2}+0,0063 x_{1} x_{2}$ & 0,9927 & 0,000053 & 0,7162 \\
\hline
\end{tabular}
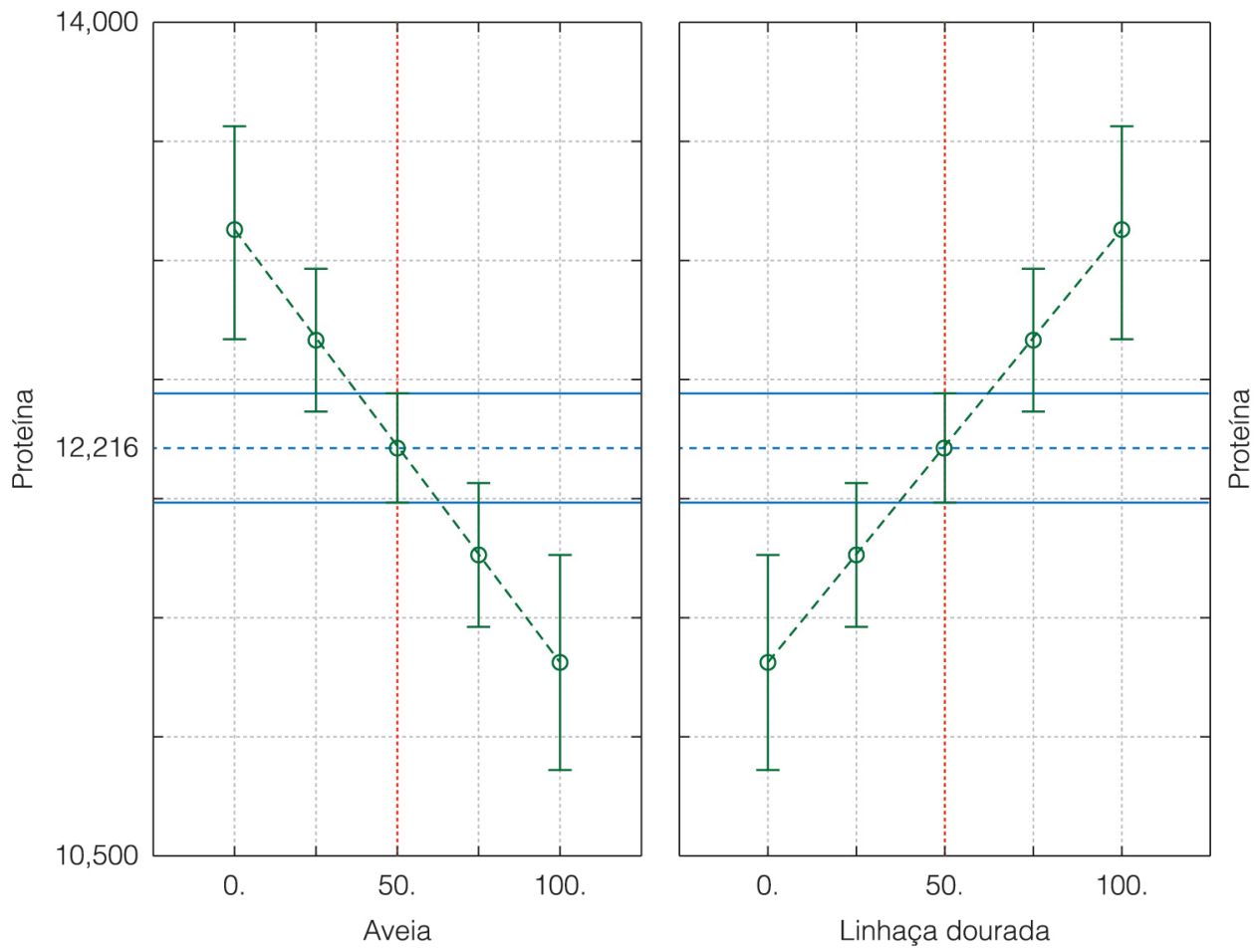

Figura 1. Proteína de barras de cereais elaboradas com aveia e linhaça dourada. As formulações utilizadas foram: T1 (100\% aveia e 0\% linhaça dourada); T2 (0\% aveia e 100\% linhaça dourada); T3, T4 e T5 (50\% aveia e 50\% linhaça dourada); T6 (25\% aveia e $75 \%$ linhaça dourada) e T7 (75\% aveia e 25\% linhaça dourada).

teores encontrados por Brito et al. (2004), ao avaliarem barras de cereais caseiras, e por Sampaio et al. (2010), que elaboraram barras de cereais fortificadas com ferro.

O teor de fibra alimentar total das barras de cereais elaboradas com aveia e linhaça dourada foi de 11,2 a $19,46 \%$ (Figura 2), sendo possível classificar as mesmas como produto de alto teor de fibra alimentar. De acordo com Brasil (2005), o produto sólido deve conter, no mínimo, $6 \mathrm{~g}$ fibras por $100 \mathrm{~g}$ para ser classificado como tal. Esses valores foram similares aos encontrados por Gutkoski et al. (2007), ao elaborarem barras de cereais à base de aveia com alto teor de fibra alimentar, e superiores ao encontrado por Freitas e Moretti (2006), ao estudarem barras de cereais com alto teor proteico e vitamínico, cuja concentração de fibras foi 5,17\%.
O valor calórico total das barras de cereais variou entre 324,11 e 421,84 kcal (Figura 3). Brito et al. (2004), estudando o valor calórico total de barras de cereais caseiras e industrializadas, encontraram valores inferiores aos do presente estudo. Com o aumento da concentração de linhaça dourada, ocorreu elevação dos teores de proteínas, lipídios, fibras, cinzas, valor calórico e redução de carboidratos, em virtude de a linhaça dourada apresentar altos teores destes nutrientes. Estes constituintes fazem da linhaça dourada um alimento funcional por ser o único com esse perfil. A alta concentração de fibras, lignanas e ômega-3 confere características de alimento funcional, devido às propriedades benéficas à saúde encontradas na linhaça dourada (BUTT et al., 2008). 

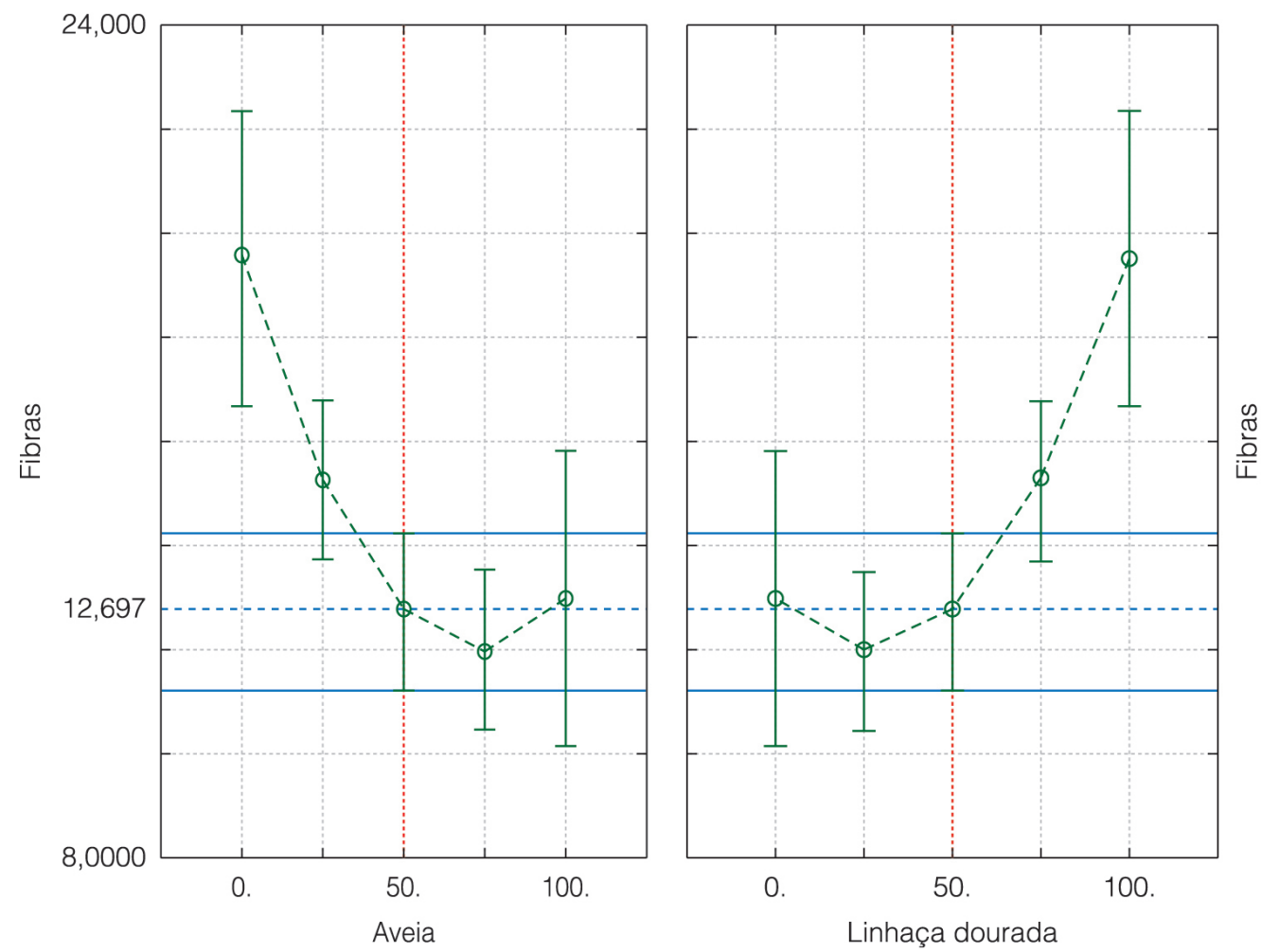

Figura 2. Fibras de barras de cereais elaboradas com aveia e linhaça dourada. As formulações utilizadas foram: T1 (100\% aveia e 0\% linhaça dourada); T2 (0\% aveia e 100\% linhaça dourada); T3, T4 e T5 (50\% aveia e 50\% linhaça dourada); T6 (25\% aveia e $75 \%$ linhaça dourada), e T7 (75\% aveia e 25\% linhaça dourada).
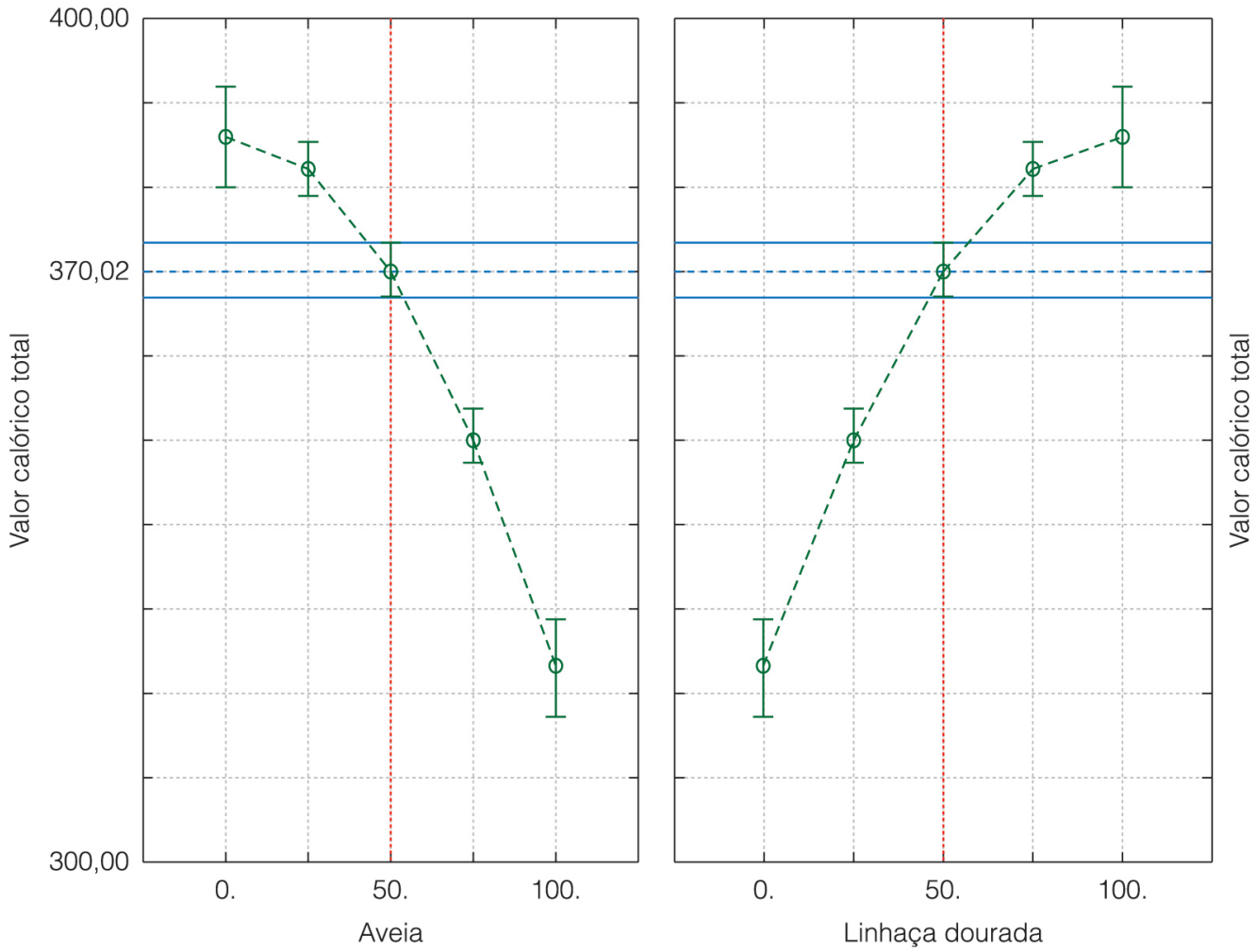

Figura 3. Valor Calórico Total (VCT) de barras de cereais elaboradas com aveia e linhaça dourada. As formulações utilizadas foram: T1 (100\% aveia e 0\% linhaça dourada); T2 (0\% aveia e 100\% linhaça dourada); T3, T4 e T5 (50\% aveia e 50\% linhaça dourada); T6 (25\% aveia e 75\% linhaça dourada), e T7 (75\% aveia e 25\% linhaça dourada). 
Aceitabilidade e estabilidade físico-química de barras de cereais elaboradas à base de aveia e linhaça dourada COLUSSI, R. et al.

\section{Conclusões}

As barras de cereais apresentam aceitabilidade sensorial nos atributos textura, aroma/odor, sabor e impressão global, quando elaboradas com proporções iguais de aveia e linhaça dourada. As barras de cereais apresentam boa estabilidade devido à baixa atividade de água e à não formação de peróxidos no período de 60 dias de armazenamento.

A combinação de aveia e linhaça dourada pode ser utilizada na elaboração de barras de cereais por apresentar composição química própria, conferindo características de um alimento funcional com alto teor de fibras.

\section{Agradecimentos}

Ao Conselho Nacional de Desenvolvimento Científico e Tecnológico (CNPq) e à Fundação de Amparo à Pesquisa do Estado do Rio Grande de Sul (FAPERGS), pela concessão de Bolsas, e à Empresa Cisbra, pela doação de linhaça e aveia.

\section{Referências}

AMERICAN ASSOCIATION CEREAL CHEMISTS - AACC. AACC International Approved Methods of Analysis. 11th ed. Saint Paul: AACC, 2009. Disponível em: <http://methods.aaccnet. org/>. Acesso em: 01 fev. 2013.

AGUIAR, L. P.; FIGUEIREDO, R. W.; ALVES, R. E.; MAIA, G. A.; SOUZA, V. A. B. Caracterização de Genótipos de Bacurizeiro. Ciência e Tecnologia de Alimentos, Campinas, v. 28 , n. 2, p. 423-428, 2008. http://dx.doi.org/10.1590/S010120612008000200024

BARROS NETO, B.; SCARMINIO, I. S.; BRUNS, R. E. Como Fazer Experimentos. Campinas: Editora da Unicamp, 2003, 401 p.

BLIGH, E. G.; DYER, W. J. A rapid method of total lipid extraction and purification. Canadian Journal of Biochemistry and Physiology, Ottawa, v. 37, n. 8, p. 911-917, 1959. http://dx.doi. org/10.1139/059-099

BOUSTANI, P.; MITCHELL, V. W. Cereal bars: a perceptual, chemical and sensory analysis. British Food Journal, London, v. 92, n. 5, p. 17-22, 1990. http://dx.doi. org/10.1108/00070709010003652

BRASIL. Ministério da Saúde. Agência Nacional de Vigilância Sanitária. Resolução RDC n 360, de 23 de dezembro de 2003. Aprova Regulamento Técnico sobre Rotulagem Nutricional de Alimentos Embalados, tornando obrigatória a rotulagem nutricional. Diário Oficial da República Federativa do Brasil, Brasília, 26 de dezembro de 2003. Seção 1.

BRASIL. Ministério da Saúde. Agência Nacional de Vigilância Sanitária. Dispõe sobre alimentos com alegações de propriedades funcionais devendo os valores atender a
Resolução-RDC n² 27, de 13 de janeiro de 1998 quanto à informação nutricional complementar. Diário Oficial da República Federativa do Brasil, Brasília, 13 de janeiro de 2005.

BRITO, I. P.; CAMPOS, J. M.; SOUZA, T. F. L. de; WAKIYAMA, C.; AZEREDO, G. A. de. Elaboração e avaliação global de barra de cereais caseira. Boletim Ceppa, Curitiba, v. 22, n. 1, p. 35-50, 2004.

BUTT, M. S.; TAHIR-NADEEM, M.; KHAN, M. K. I.; SHABIR, R.; BUTT, M. S. Oat: unique among the cereals. European Journal of Clinical Nutrition, London, v. 47, n. 2, p. 68-79, 2008.

COLPO, E.; FRIEDRICH, L.; ROSA, C. S; OLIVEIRA, V. R. Benefícios do uso da semente de linhaça. Nutrição em Pauta, São Paulo, v. 14, n. 81, p. 25-28, 2006.

FENNEMA, O. R. Química de los Alimentos. 2. ed. Zaragoza: Acribia, 2000. p. 19-110.

FIRESTONE, D. (Ed.) Official methods and recommended practices of AOCS. 6th ed., Champaign: AOCS, 2012, v. 3, $1200 \mathrm{p}$.

FREITAS, D. G. C.; MORETTI, R. H. Caracterização e avaliação sensorial de barras de cereais funcional de alto teor protéico e vitamínico. Ciência e Tecnologia de Alimentos, Campinas, v. 26 , n. 2, p. 318-324, 2006. http://dx.doi.org/10.1590/S010120612006000200014

GALDEANO, M. C.; GROSSMANN, M. V. E.; MALI, S.; BELLOPEREZ, L. A. Propriedades físico-químicas do amido de aveia da variedade brasileira IAC 7. Ciência e Tecnologia de Alimentos, Campinas, v. 29, n. 4, p. 905-910, 2009. http://dx.doi. org/10.1590/S0101-20612009000400031

GALVÃO, E. L.; SILVA, D. C. F.; SILVA, J. O.; MOREIRA, A. V. B.; SOUZA, E. M. B. D. Avaliação do potencial antioxidante e extração subcrítica do óleo de linhaça. Ciência e Tecnologia de Alimentos, Campinas, v. 28, n. 3, p. 551-557, 2008. http:// dx.doi.org/10.1590/S0101-20612008000300008

GUTKOSKI, L. C.; BONAMIGO, J. M. A.; TEIXEIRA, D. M. F.; PEDÓ, I. Desenvolvimento de barras de cereais à base de aveia com alto teor de fibra alimentar. Ciência e Tecnologia de Alimentos, Campinas, v. 27, n. 2, p. 355-363, 2007. http:// dx.doi.org/10.1590/S0101-20612007000200025

GUTKOSKI, L. C.; TEIXEIRA, D. M. F.; DURIGON, A.; GANZER, A. G.; BERTOLIN, T. E.; COLLA, L. M. Influência dos teores de aveia e de gordura nas características tecnológicas e funcionais de bolo. Ciência e Tecnologia de Alimentos, Campinas, v. 29, n. 2, p. 254-261, 2009. http://dx.doi.org/10.1590/S010120612009000200003

IZZO, M.; NINESS, K. Formulating nutrition bars with inulin and oligofructose. Cereal Foods World, Minneapolis, v. 46, n. 3 , p. 102-105, 2001.

KLAJN, V. M.; GUTKOSKI, L. C.; ELIAS, M. C. Atividade antioxidante em grãos de cereais. In: GUTKOSKI, L. C. (Ed.). 
Aceitabilidade e estabilidade físico-química de barras de cereais elaboradas à base de aveia e linhaça dourada COLUSSI, R. et al.

Malte e extrato de malte: aveia, milho e trigo. Passo Fundo: Imperial, 2012. Cap. 5, p. 177-217.

LATIMER Jr., G. W. (Ed.) Official Methods of Analysis of the Association of Official Analytical Chemistry. 19th ed., Arlington: AOAC, 2012. 2 v.

MARQUART, L.; JACOBS, D. R.; SLAVIN, J. L. Whole grains and health an overview. Journal of the American College Nutrition, Nova York, v. 19, n. 3, p. 289-290, 2000.

PETERSON, D. M., EMMONS, C. L., HIBBS, A. H. Phenolic antioxidants and antioxidant activity in pearling fractions of oat groats. Journal of Cereal Science, London, v. 33, n. 1, p. 97-103, 2001. http://dx.doi.org/10.1006/jcrs.2000.0347
PIOVESANA, A.; BUENO, M. M.; KLAJN, V. M. Elaboração e aceitabilidade de biscoitos enriquecidos com aveia e farinha de bagaço de uva. Brazilian Journal of Food Technology, Campinas, v.16, n. 1, p. 68-72, 2013. http://dx.doi.org/10.1590/ S1981-67232013005000007

SAMPAIO, C. R. M.; FERREIRA, S. M. R.; CANNIATTI-BRAZACA, S. G. Caracterização físico-química e composição de barras de cereais fortificadas com ferro. Alimentos e Nutrição, Araraquara, v. 21, n. 4, p. 607-616, 2010.

STONE, H. S.; SIDEL, J. L. Sensory Evaluation Practies. 2. ed. San Diego: Academic Press, 1993, 338 p. 